\title{
Design of Lower Limb Exoskeleton using Gearbox for Rehabilitation of Paralyzed Patients
}

\author{
Sanket.M.Sapkal, Ashish.A.Sakore, Vedant.A.Watane, Malakarisiddha.D.Rathod, \\ Yogesh.L. Maske
}

\begin{abstract}
The number of people with mobility disorder cause by stroke spinal cord injury or related disease is increasing rapidly.To improve quality of life of this people device that can assist them to regain the ability to work are of great demand. Robotic devices are generally used for purpose.The aim of this paper is to present the design and analysis of lower limb exoskeletons. The Exoskeleton is designed by Mechanical Design Procedure for linkages and against the Position values obtained from Gait Analysis.The Gearbox is designed using standard design procedure. This exoskeleton work on the principle of robotics by using sensors, actuator like DC motor. Gait analysis is used as a primary analysis followed by static and dynamic analysis of designed model.Static and Dynamic Analysis is performed in ANSYS Workbench. This exoskeleton will be used for paralyzed patient (paraplegia)as well as for the people who have had accidents for lower body.The limitation of this work is the same exoskeleton cannot be used for all person and a small defect in sensor and other electronic devices will stop the exoskeleton. Using this exoskeleton a paralyzed patient will be able to rehabilitate they will be able to perform stand to sit motion.
\end{abstract}

Keywords: Dynamic Analysis,Gait Analysis,Lower Limb Exoskeleton

\section{INTRODUCTION}

Around the world every year 250000 to 500000 people suffers spinal cord injury (SCI)[1].The majority of the spinal cord injuries are due to anthropogenic activities such as road accidents, falls or violence. Spinal cord injury may require a person to be dependent on the caregivers. According to Fourth European survey on working conditions, 35\% of plant and machine operators and assemblers report having regular backaches and muscular pains[3] In view of the ageing of working population the reduction of physical risk has emerged as priority topic[2].As human age they start to have physical and cognitive disease which become severe and they are

Revised Manuscript Received on May 15, 2020.

* Correspondence Author

Sanket.S.Sapkal*, School of Mechanical and Civil Engineering, MIT Academy of Engineering, Pune, India. Email: sanket-sapkal@mitaoe.ac.in

Ashish.A.Sakore, School of Mechanical and Civil Engineering, MIT Academy of Engineering, Pune, India. Email: aasakore@mitaoe.ac.in

Vedant.A.Watane, School of Mechanical and Civil Engineering, MIT Academy of Engineering, Pune, India. Email: vawatane@mitaoe.ac.in

Malakarisiddha.D.Rathod, School of Mechanical and Civil Engineering, MIT Academy of Engineering, Pune, India. Email: mdrathod@mitaoe.ac.in

Yogesh.L.Maske, Assistant Professor in School of Mechanical and Civil Engineering, MIT Academy of Engineering, Pune, India. Email: ylmaske@mitaoe.ac.in

(C) The Authors. Published by Blue Eyes Intelligence Engineering and Sciences Publication (BEIESP). This is an open access article under the CC BY-NC-ND license (http://creativecommons.org/licenses/by-nc-nd/4.0/) unable to perform basic daily living activities like walking,running[2].To facilitate mobility and perform different activities like communication, self care or domestic activities assistive technology is often required. An estimated of $20-30 \%$ of people having spinal cord injury shows medically significant signs of depression which in turn has a negative impact on mental health and functioning of human body. Assistive devices include robotic devices which help the paralyzed patients to regain the ability to stand and walk[2]. During the past decade a large number of development has occurred in the field of Lower Limb Exoskeleton(LEE).LEE are human-wearable systems which provide human mobility.LEE consist of actuators which applies torque to the joints .LEE's integrate both human intelligence and robot power[2].Existing exoskeleton comes at a very large cost which is affordable to lower number of population. Along with cost, wearable exoskeleton are rigid and are not comfortable. In this paper we present design and analysis of wearable exoskeleton named Saksham to help paralyzed patients to perform daily essential human activities such as stand up and walk. Exoskeleton structure design in such way that to ensure maximum coherent between wearers motion with exoskeleton and with reduction in weight of the exoskeleton structure.

\section{MATERIALS}

In designing of an exoskeleton, a material that is light and strong is required to form the frame of the exoskeleton. This is because lighter frame means lesser power is required to actuate the body part. However, the frame of the exoskeleton should be hard enough to withstand the torque generated by the actuator and also the body weight of the wearer. Aluminium alloys are chosen as main material for the frame of the exoskeleton. Different types of Aluminium alloys are used in different studies, the main reason Aluminium alloys is one of the most popular material is because of its lightness and strength. Combination of Duralium or Aluminium 2024 and stainless steel is used to construct the structure of the exoskeleton[4].The Aluminium alloy 7075 are used in high load structure whereas the polyamide 6 are applied in low load structure to make the exoskeleton as light as possible. The prosthetic Aluminum tubing is chosen because it is designed for human use and very light. Carbon fibers are only used in a small portion because it is very expensive despite the fact that it is lighter than Aluminium[4].For exoskeleton robot, mechanical and physical properties of materials are considered. These properties are especially tensile strength, yield strength, shear strength, density and magnetic property. Table I shows the comparison of materials used for exoskeleton on basis of Yield Strength,

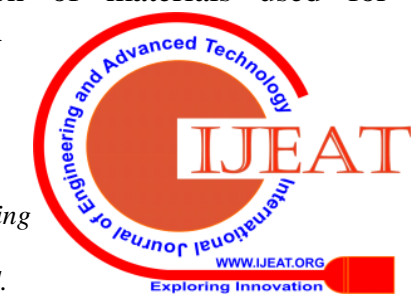


Table-I: Comparison of Materials on basis of different mechanical properties [4]

\begin{tabular}{|c|c|c|c|c|}
\hline Metal/Alloy & $\begin{array}{c}\text { Yield } \\
\text { Strength(Mpa) }\end{array}$ & $\begin{array}{c}\text { Tensile Strength } \\
(\mathrm{Mpa})\end{array}$ & Density $\left(\mathrm{kg} / \mathrm{m}^{3}\right)$ & $\begin{array}{c}\text { Shear } \\
\text { Strength(Mpa) }\end{array}$ \\
\hline Gray Cast Iron & 135 & 170 & 7830 & 45 \\
\hline Aluminium 1100 & 105 & 110 & 2710 & 28 \\
\hline Alumin.2024-T3 & 345 & 483 & 2768 & 30 \\
\hline Steel AISI 302 & 520 & 860 & 7850 & 186 \\
\hline Aluminium 7068 & 590 & 641 & 2875 & 365 \\
\hline
\end{tabular}

Tensile Strength,Density,Shear Strength. Aluminium 2024 T3 have better properties than Gray CI and Aluminium 1100 but low as compared to Steel and Aluminium 7068.Steel is heavy as compared to Aluminium and will increase the weight of exoskeleton. Aluminium 2024 T3 alloy is selected as material for Exoskeleton frame.

\section{GAIT ANALYSIS}

Gait Analysis is a systematic study of human motion for measuring body movements, busy mechanics and activity of muscles[5]. Angulus android application was used to perform GAIT Analysis. Angulus measures angles on images and videos. It is ideal for joint range measurement. A video was recorded of a human being walking on a trade mill and that was used as a input to the Application. The Application converts the video into images at different time interval. According to requirement images are selected. Reference point is then marked on images and using 3-point angle is calculated. Fig. 1 shows the images which are selected and analyzed.
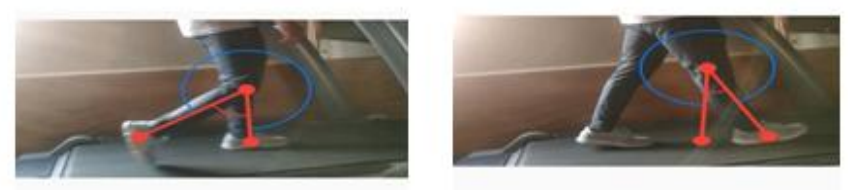

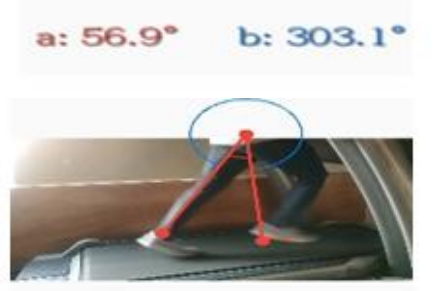

$a: 33.6^{\circ} \quad b: 326.4^{\circ}$
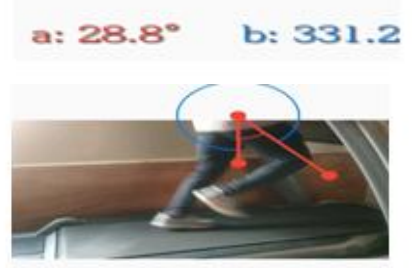

a: $40.4^{\circ}$

b: $319.6^{\circ}$
Fig. 1. Result of Gait Analysis

With the help of trade mill angles are measured for different situation like walk, running at knee, hip. By using these values of angle Torque is calculated at various positions.

\section{DESIGN CONSIDERATIONS}

\section{A.Link lengths}

The Link lengths between hip,knee and ankle are calculated from standard properties of male and female[6].Average height of human body is taken as $164 \mathrm{~cm}$.Using this value other values are calculated.The dimensions are, Hip to Knee $=41 \mathrm{~mm}$, and Knee to Ankle $=46 \mathrm{~mm}$

\section{B. Torque}

Weight of human considerd is $70 \mathrm{~kg}$ and from weight of human body parts as percentage of total body weight force is calculated for perticular body parts. From that force obtained by torque values are calculated.Mathematically,Torque= $\mathrm{L} * \mathrm{~F} * \mathrm{SIN} \theta$ where, $\mathrm{F}=\mathrm{M} * \mathrm{~g}$, = Mass of body part,L= Length of body part, $\theta=$ Angle at joint position[7].By using this formula torque is calculated at different position of leg.The calculated torques are Torque at Hip $=91$ N.m and Torque at Knee $=80$ N.m

\section{Motor Selection and Gearbox Design}

Wearable exoskeleton require actuators for the movement of limbs.Linear electronic motors,Hydraulic and Pneumatic actuators are mostly used.For the use of this necessary components like pressurized oil and compressed air are required.Harmonic drives are highly efficient for actuation but thr problem associated with harmonic drives is that they are extremely costly[8].The use of such harmonic drives increases the total cost of the exoskeleton which in turn decreases the chances of its getting used by people with poor financial conditions So in present work as a optional to harmonic drive a mechanical gearbox is used for controlling of torque.The torque from motor is stepped up by using a step up gearbox.The calculations for gearbox are performed using standard procedure as mentioned in the design data book[9][10].Table 2 and

Table-II: Gearbox at Hip Joint

\begin{tabular}{|l|l|}
\hline Gearbox & Two-Stage Helical Gearbox \\
\hline Gear ratio & $2: 10$ \\
\hline Module & $2 \mathrm{~mm}$ \\
\hline Diameter of pinion & $36 \mathrm{~mm}$ \\
\hline Diameter of gear & $76 \mathrm{~mm}$ \\
\hline Output speed & $27 \mathrm{rpm}$ \\
\hline Output torque & $91 \mathrm{~N}-\mathrm{m}$ \\
\hline
\end{tabular}

Table-III:Gearbox at Knee Joint

\begin{tabular}{|l|l|}
\hline Gearbox & Two-Stage Helical Gearbox \\
\hline Gear ratio & $3: 18$ \\
\hline Module & $2 \mathrm{~mm}$ \\
\hline Diameter of pinion & $36 \mathrm{~mm}$ \\
\hline Diameter of gear & $106 \mathrm{~mm}$ \\
\hline
\end{tabular}

\section{Published By:}

Blue Eyes Intelligence Engineering \& Sciences Publication 


\begin{tabular}{|l|l|}
\hline Output speed & $30 \mathrm{rpm}$ \\
\hline Output torque & $80 \mathrm{~N}-\mathrm{M}$ \\
\hline
\end{tabular}

Table 3 shows the different dimensions of gears which are calculated at Hip and Knee.

\section{MODELLING}

After calculation of necessary components and selection of mechanical components like clamps,nut-bolts,couplers the 3D modelling is performed in Software.The material is reduced by pocketing the model so as to reduce the weight of body.Hooks are provided at points so that the exoskeleton can be tightly fitted.As seen in Fig.2 the motor provides the driving force to the limbs.The motor is controlled by a micro-controller which recieves its input from different sensors like IMU,pressure sensors. The torque from the motor is stepped-up by using gearbox.The output shaft of the gearbox is connected to the hip joints of the exsokeleton from where movement of hip is performed.Similiarly the hip movement is also performed by using the combination of gearbox and motor.

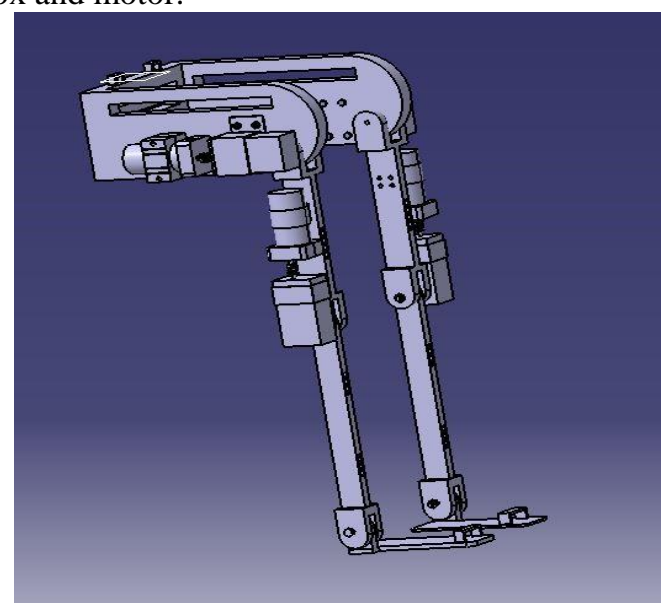

Fig. 2.CATIA Model of Designed Exsokeleton

\section{RESULT AND DISCUSSION}

The model is then analyzed in ANSYS Workbench for different parameters like Stress,Deformation,Accelaration.The design is imported.For analysis purpose the components like Gearbox,Motor,Clamps and Couplers are removed from the model.The weight of these components are resolved into point load and made to act on model.Various properties for Aluminium T3 such as Density,Ultimate strength are provided in Enginnering Data section.The model is then meshed with default meshing settings of of Workbench.The body weight is divided into various sections so the loads could be made to act accordingly. The loads are made to act on the inner surface of the limbs in downward direction.In the initial stage static analysis is performed.The orientation of the model is changed where the probability of failure of model tends to maximum.The orientation is such that one leg of the exoskeleton is made at its maximum permissibility of extension.At this orientation the probability to fail is maximum.The model is then analyzed for Equivalent Stress and Total Deformation.As shown in Fig. 3 the maximum stress obtained in the analysis is $155 \mathrm{Mpa}$ which is less than the Ultimate Stress of Aluminium model is safe against all the conditions. After the initial stage of static analysis has produced the desired results dynamic analysis is performed on exoskeleton.For Dynamic analysis Rigid Dynamics in ANSYS Workbench is used.In rigid dynamics the model is imported.Similiar to the static analysis the engineering data for Aluminium T3 is selected.The necessary joints are applied like Body-Ground Joint,Cylindrical Joint,Revolute Joint in contact window of workbench.The joint loads are then applied on the joints at Hip,Knee and Ankle.The boundary conditions for position are applied with the values obtained from Gait Analysis.The model is meshed with default meshing settings of Workbench.The solution is performed for Total Deformation and Total Accelaration.As shown in Fig.4 the Total Deformation in dynamic motion of Exoskeleton is obtained in limit to the permissible deformation by aluminuim. Table IV shows the combined results of static and dyanamic analysis. So it can be validated that the proposed model is safe against static analysis as well as dynamic analysis.
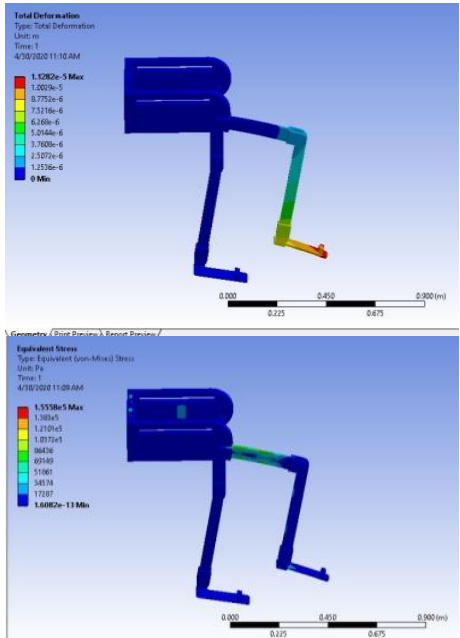

Fig 3. Stress and Deformation results of Static Analysis
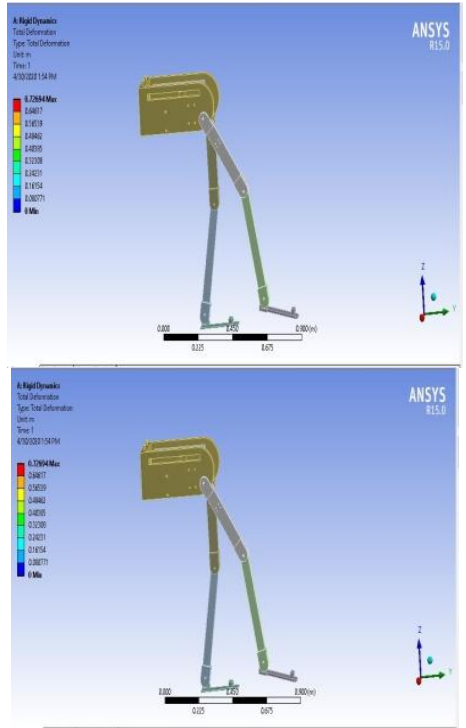

Fig. 4. Deformation and Accelaration Results of Dynamic Analysis

Published By:

Blue Eyes Intelligence Engineering

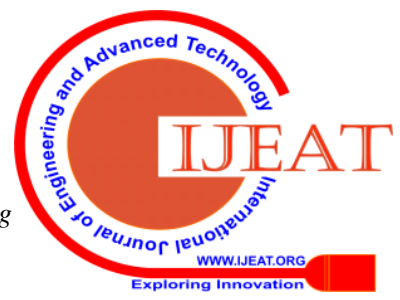


Table - IV Validation of Results

\begin{tabular}{|l|l|c|}
\hline \multicolumn{1}{|c|}{ Analysis } & \multicolumn{1}{|c|}{ Parameter } & Value \\
\hline Static Analysis & Equivalent Stress & $155 \mathrm{Mpa}$ \\
\cline { 2 - 3 } & Total Deformation & $1.98 \mathrm{~mm}$ \\
\hline \multirow{2}{*}{ Dynamic Analysis } & Total Deformation & $5.7269 \mathrm{~mm}$ \\
\cline { 2 - 3 } & Total Accelaration & $0.0872 \mathrm{~m} / \mathrm{s}^{2}$ \\
\hline
\end{tabular}

\section{CONCLUSION}

The values of position of Hip and Knee Joint while walking were recorded by using Gait Analysis. These values are further used in Design as well as providing boundary condition in Static and Dynamic analysis. The value of Torques can be calculated from position values from Gait Analysis and later used in Analysis. Gearbox can be used as torque variation method in exoskeleton with an advantage of low cost as compared to Harmonic Drive. Aluminium 2024 T3 with its useful properties proves a significant material in manufacturing of exoskeleton. Density of Aluminium is less hence it results in less weight of Exoskeleton. The exoskeleton when manufactured by the data provided in this paper will be manufactured at low cost which will be affordable to people with poor financial condition.

\section{REFERENCES}

1. 1.World Health Organization,World Health Stastics 2020[Accessed 15 January 2020].

2. B.S.Rupal, S. Rafique, A.Singla, E. Singla, “Lower-limb exoskeletons: research trends and regulatory guidelines in medical and non-medical applications" International Journal of Advanced Robotic Systems,2017, pp.1-27

3. E. Schneider, , S. Copsey, , X. Irastorza, "Occupational Safety and Health ”, Work-related Musculoskeletal Disorders in the EU-Facts and Figures, Office for Official Publications of the European Communities, 2010.

4. A. Latif, T. Chee Jun, S. Md Isa,"Torque Analysis of the Lower Limb Exoskeleton Robot Design" Asian Research Publishing Network,2017, 54, pp.78-93.

5. B. chen, C.H Zhong, X. Zhao , H. Ma , Xiao Guan, "A wearable exoskeleton suit for motion assistance to paralyzed patients" journal of orthopedic translation 11,2017,pp. 7-18

6. 6.Hipolito Aguilar-Sierra,Wen Yu Sergio,Ricardo Lopez, "Design and Control of hybrid actuation lower limb exoskeleton",Advances in Mechanical Ebgineering,2015,pp.2-5

7. A. Singla, S. Dhand, G. Singh Virk, " Mathematical modeling of a hand crank generator for powering lower limb exoskeletons" ,Perspectives in science 8,2016, pp.561-563.

8. Ashish Singla,Baltej Singh Rupal, "Optimization of stepped-cone CVT for lower limb exoskeleton",Perspectives in Science,2016,pp.592-595

9. 9.Bhandari V.B, "A text-book of Machine Design",3 edition,McGraw Hill,2011,pp.703-720.

10. 10.PSG College of Engineering, “Design Data",Kalaikathir Achchagam,2012,1.2-1.5.

\section{AUTHORS PROFILE}

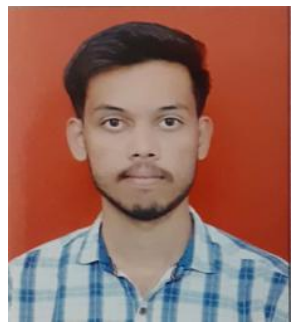

Sanket.M.Sapkal, is a student of M.I.T Academy of Engineering, Alandi in which he is pursuing bachelor of technology in Mechanical engineering. He has an overall CGPA of 7.65 and excellent knowledge in Mechanical stream. With excellent academic results in 10th and under graduation, he has planned to pursue $\mathrm{M}$. Tech in future. Due to his curiosity in the field of robotics and automation, he also want to serve to e D.R.D.O which is an agency in India working under ministry of defense.

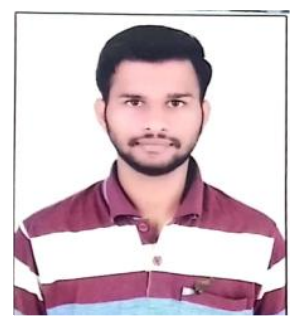

Ashish.A.Sakore, is a student of M.I.T Academy of Engineering, Alandi, in which he is pursuing bachelor of technology in Mechanical engineering. He has an overall CGPA of 8.6 and sufficient knowledge in mechanical stream. With excellent academic results in 10th and under graduation, he has completed both this in pune. he has plan to pursue $\mathrm{M}$. Tech in future due to his curiosity in the field of computer languages and artificial intelligence. He love to learn new trends in computer domain.

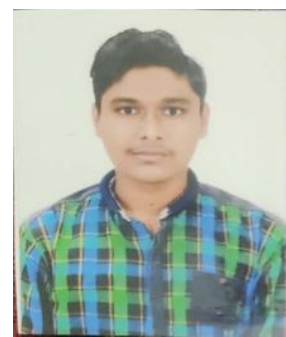

Vedand A. Watane, is a student of M.I.T Academy of Engineering, Alandi.in which he is pursuing bachelor of technology in mechanical engineering. He has an overall CGPA of 8.55 and excellent knowledge in mechanical stream. With excellent academic results in 10th and under graduation, he has been working on to build skills which would match him to the profile of IAS. He has been sincerely working on government exam in order to get chance to serve the nation.

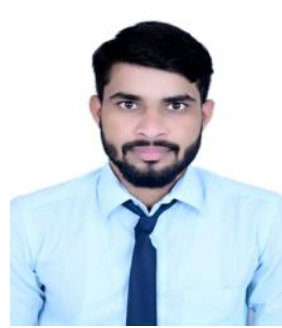

Malakarisiddha Rathod, is a student of M.I.T Academy of Engineering, Alandi. in which he is pursuing bachelor of technology in Mechanical engineering. He has an overall CGPA of 8.26 and excellent knowledge in mechanical stream. With excellent academic results in 10th and under graduation, he has plan to learn economics, due to his interest in Indian economy and politics, he also want to serve his village by becoming corporator.

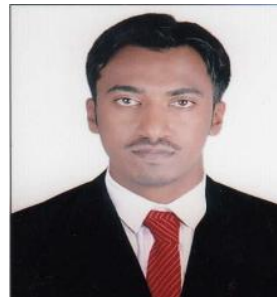

Yogesh.L.Maske, is Assistant Professor in School of Mechanical and Civil Engineering of MIT Academy of Engineering Alandi Pune India .He has completed his Master of Engineering in Mechanical Design and his area of interest is Robotics and Automation. He is currently member of SAE INDIA and ISTE

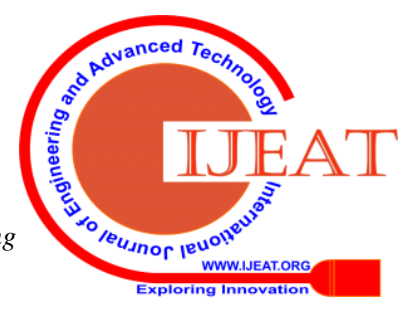

